\title{
Rome was not built in a day
}

\author{
Ko Bando, MD, PhD
}

See related article on pages e92-4 in the June 2015 issue.

The evolution of transcatheter heart valve procedures during the past 10 years has introduced profound changes to the treatment of heart valve disease. ${ }^{1,2}$ Several studies have described promising outcomes associated with valve-in-valve procedures in both the aortic ${ }^{3}$ and mitral $^{4}$ positions. This technology has been subsequently applied to valve-in-ring and valve-in-native-ring procedures for the mitral position with excellent short-term outcomes. A prior implanted radiopaque bioprosthesis or annuloplasty ring can provide a good target for determining the landing zone. $^{5}$

In the June 2015 issue of the Journal, Wilbring and colleagues ${ }^{6}$ describe their experience with a successful mitral valve-in-ring procedure in the absence of radiopaque annuloplasty rings. In this unique case, prior mitral repair was performed using an SJM-Seguin annuloplasty ring ( $\mathrm{St}$ Jude Medical Inc, St Paul, Minn), but fluoroscopy was not helpful because this particular ring is radiolucent. However, they were able to determine the final landing zone using continuous 2-dimensional echocardiography with stepwise 3-dimensional confirmation. Their remarkable success shows that mitral valve-in-ring transcatheter aortic valve implantation (TAVI) can be performed even in the absence of radiopaque markers, but at the same time, we have to remind ourselves that these types of advanced procedures can only be performed in centers with substantial experience. ${ }^{7}$

As mentioned in the Discussion, ${ }^{6}$ this is far from a simple procedure. Proper alignment of the valve in the center of the annuloplasty ring requires a step-by-step combination of both 2-dimensional and 3-dimensional reconstructions of the echocardiograph. Displaying the entire field, which includes both the top and bottom of the valve along with the annuloplasty ring, is considerably more difficult in this method and it cannot be considered as accurate as conventional fluoroscopy.

We must keep in mind that the authors performed more than 550 TAVI procedures, ${ }^{5}$ including more than 300

\footnotetext{
From the Department of Cardiac Surgery, The Jikei University School of Medicine, Tokyo, Japan.

Disclosures: Author has nothing to disclose with regard to commercial support.

Received for publication May 9, 2015; accepted for publication May 12, 2015; available ahead of print July 14, 2015.

Address for reprints: Ko Bando, MD, PhD, 3-25-8, Nishi Shinbashi, Minatoku, Tokyo 105-8461, Japan (E-mail: kobando@ jikei.ac.jp).

J Thorac Cardiovasc Surg 2015;150:e49-50

$0022-5223 / \$ 36.00$

Copyright (c) 2015 by The American Association for Thoracic Surgery

http://dx.doi.org/10.1016/j.jtcvs.2015.06.025
}

using the transapical approach $^{4}$ and more than 14 mitral TAVI procedures, ${ }^{5}$ before tackling this difficult problem.

There is no question that having an efficient multidisci-

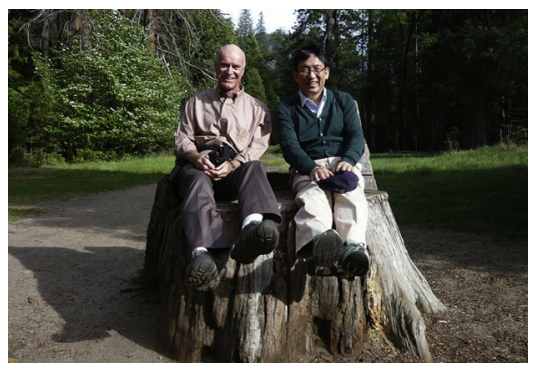
plinary team is a key component in achieving successful outcomes with this type of challenging procedure. Such an efficient heart team cannot be built in a short period of time: Rome was not built in a day. Solid mutual confidence among interventional cardiologists, cardiac surgeons, anesthesiologists, echocardiologists, and other team members should be nourished over time in daily preprocedural patient evaluation and selection, preprocedural briefings, and intraoperative communication, as well as through the analysis of longitudinal outcomes.

This innovative approach does, however, leave us with several concerns. First, experience with this valve-in-ring procedure is limited, and the follow-up period described ${ }^{6}$ is quite short. Thus, long-term durability of this procedure remains uncertain. Second, the majority of patients with failed mitral repair may have concomitant tricuspid regurgitation $^{5}$ and this new approach does not provide a good solution for residual tricuspid regurgitation. Third, this valve-in-ring approach has been applied only to rigid or semirigid rings, and thus cannot provide an adequate solution for high-risk patients who have previously had partial bands implanted. Lastly, an appropriate anticoagulation regimen has not been established. ${ }^{5}$ Although TAVI patients for aortic valves usually do not require anticoagulation with warfarin, a recent report ${ }^{5}$ indicated that this may not be the case because 2 out of 13 mitral valve-in-valve/valve-in-ring patients developed signs of valve thrombosis 8 weeks and 3 months after surgery, respectively. ${ }^{5}$

I applaud Wilbring and colleagues for their pioneering work in valve-in-ring mitral procedures. However, the long-term results should be cautiously monitored until proper indications and a follow-up regimen can be more clearly defined.

\section{References}

1. Smith CR, Leon MB, Mack MJ, Miller DC, Moses JW, Svensson LG, et al. Transcatheter vs surgical aortic-valve replacement in high risk patients. $N$ Engl J Med 2011;364:2187-98.

2. Kodali SK, Williams MR, Smith CR, Svensson LG, Webb JG, Makkar RR, et al Two-year outcomes after transcatheter or surgical aortic valve replacement. $N$ Engl J Med. 2012;366:1686-95. 
3. Dvir D, Webb JG, Bleiziffer S, Pasic M, Walksman R, Kodali S, et al. Transcatheter aortic valve implantation in failed bioprosthetic surgical valves. JAMA. 2014; 312:162-70

4. Wilbring M, Alexiou K, Tugtekin SM, Sill B, Hammer P, Schmidt T, et al. Transapical transcatheter valve-in-valve implantation for deteriorated mitral valve bioprostheses. Ann Thorac Surg. 2013;98:111-8.

5. Wilbring M, Alexiou K, Tugtekin SM, Arzt S, Ibrahim K, Matschke K, et al. Pushing the limits-further evolutions of transcatheter valve procedures in the mitral position, including valve-in-valve, valve-in-ring, and valve-in-native-ring. $J$ Thorac Cardiovasc Surg. 2014;147:210-9.

6. Wilbring M, Kappert U, Matschke K. Transapical transcatheter valve-in-ring implantation for failed mitral valve repair in the absence of radiopaque markers. $J$ Thorac Cardiovasc Surg. 2015;149:e92-4.

7. Tommaso CL, Fullerton DA, Feldman T, Dean LS, Hijazi ZM, Horlick E, et al. SCAI/ AATS/ACC/STS operator and institutional requirements for transcatheter valve repair and replacement. Part II. Mitral valve. J Thorac Cardiovasc Surg. 2014;148:387-400. 